American Journal of Pharmaceutical Education 2020; 84 (10) Article 7991.

\title{
REVIEW
}

\section{A Review of Development Initiatives for Pharmacy Student and Resident Preceptors}

\author{
Meredith L. Howard, PharmD, ${ }^{a}$ Wei C. Yuet, PharmD, ${ }^{b}$ Alex N. Isaacs, PharmD ${ }^{c}$ \\ ${ }^{a}$ University of North Texas System College of Pharmacy, Fort Worth, Texas \\ ${ }^{\mathrm{b}}$ JPS Health Network, Fort Worth, Texas \\ ${ }^{c}$ Purdue University, College of Pharmacy, West Lafayette, Indiana \\ Submitted January 17, 2020; accepted May 17, 2020; published October 2020.
}

Objective. To review the published literature describing and evaluating pharmacy student and resident preceptor development.

Findings. Database searches yielded 32 published articles on pharmacy preceptor development: 22 for experiential preceptors, eight for resident preceptors, and two encompassing both experiential and resident preceptors. The identified articles covered a variety of preceptor development strategies, including live, web-based, and multifaceted approaches, which were disseminated via analytical studies, needs assessment surveys, and descriptive reports. In analytical studies, the evaluation methods most commonly used were preceptor pre- and post-perception surveys.

Summary. Preceptor development strategies vary among pharmacy schools and residency programs. The evaluation methods used also varied, and there is a lack of evidence-based practices related to preceptor development. Preceptor development should be tailored based on preceptor type and program needs. An opportunity exists to further evaluate which strategies are most effective for improving precepting techniques, with an ultimate goal of delineating best practices for pharmacy preceptor development.

Keywords: preceptor development, continuing education, experiential education

\section{INTRODUCTION}

Preceptors are essential stakeholders in Doctor of Pharmacy (PharmD) programs accredited by the Accreditation Council for Pharmacy Education (ACPE) and pharmacy residency programs accredited by the American Society of Health-System Pharmacists (ASHP). ${ }^{1-3}$ Preceptors must have credentials and expertise in accordance with their roles and responsibilities, similar to the expectations for pharmacy faculty members. ${ }^{1}$ The ACPE's Standards 2016 recommend that colleges and schools of pharmacy include preceptors in critical areas such as strategic plan development, curriculum delivery, and fostering a culture of collaboration and professionalism. ${ }^{1}$ Preceptor education, development, and engagement are also emphasized as key elements of a successful experiential education program. ${ }^{1}$ Guidance on qualifications, credentials, and development for pharmacy resident and student preceptors is further elaborated in the American College of Clinical Pharmacy (ACCP) white

Corresponding Author: Meredith L. Howard, University of North Texas System College of Pharmacy, 3500 Camp Bowie Blvd., Fort Worth, TX 76107. Tel: 817-735-2253. Email:

Meredith.Howard@unthsc.edu paper, "Quality Experiential Education."4 Both documents emphasize the importance of preceptor development support by schools and colleges of pharmacy. ${ }^{1,4}$

Preceptor challenges associated with experiential education programs are well described in the pharmacy literature. ${ }^{5-7}$ In a survey by Danielson and colleagues of 78 experiential directors, preceptor development was identified as one of eight common concerns. ${ }^{7}$ Specific examples of this concern included training preceptors and adjunct faculty members to assess student outcomes, coordinating preceptor education, and advancing practice sites. The identification of this concern was consistent among both private and public institutions regardless of student class size. The 2015-2016 American Association of Colleges of Pharmacy (AACP) Professional Affairs Standing Committee (PAC) reported similar needs after surveying representatives from nine national and state pharmacy organizations. ${ }^{8}$ Additional considerations included managing students of different learner levels, facilitating resident preceptors, and creating preceptor development plans. The 2015-2016 AACP PAC recommended that national pharmacy organizations disseminate best practices for preceptor development, which presently remains undefined. 


\section{American Journal of Pharmaceutical Education 2020; 84 (10) Article 7991.}

Although numerous modalities for preceptor development exist, there is a lack of consensus among professional organizations and state boards of pharmacy in the United States regarding requirements for preceptor development. ${ }^{8,9}$ For example, some states mandate a specific number of preceptor continuing education (CE) hours for licensure as a pharmacist preceptor. ${ }^{10}$ Additionally, it is unclear whether certain training modalities (eg, live, online, print) are more effective than others. The characterization of best practices for preceptor development would be beneficial given the variability of prior education and training among volunteer and non-volunteer preceptors. Pharmacy schools may have criteria for preceptor eligibility but largely recruit preceptors based on preceptor interest or practice site. Furthermore, the use of preceptor self-assessment tools to assist with continued professional development may not be widespread among pharmacy programs. A study at one pharmacy program in Thailand found that preceptors overestimated the quality of their teaching compared to student evaluation ratings. ${ }^{11}$ This highlights the necessity of robust preceptor development programs since preceptor teaching behaviors may impact student performance on clinical competencies. $^{12}$

Preceptor development for pharmacy residency programs is also a significant area of need. In a survey of 1437 pharmacy residency preceptors and residents, only $55.9 \%$ of respondents believed that their institution provided ample opportunities for preceptor development. ${ }^{13}$ The ASHP accreditation standards for pharmacy residency programs address two skillsets of preceptor development: teaching and professionalism. ${ }^{2,3}$ Often, it is the responsibility of the residency program director or program leadership team to evaluate preceptor teaching skills, provide opportunities for preceptor development, and implement a plan for teaching quality improvement. ${ }^{2,3}$ Pharmacy residency programs must have the resources and evidence-based approaches to train residency program directors and preceptors in the aforementioned areas.

There is a lack of uniformity within preceptor development expectations, requirements, and outcomes despite the inclusion of preceptor development in pharmacy education and residency program accreditation standards. The objective of this review was to identify best practices for pharmacy preceptor development by summarizing relevant existing literature.

\section{METHODS}

An English-language PubMed and MEDLINE search was conducted for 1964 through April 2020 using the following search terms alone or in combination: preceptor development, preceptor training, preceptor education, experiential education, pharmacy, residency preceptor, resident preceptor, and pharmacy preceptor. Two of the authors reviewed the articles to determine which to include and also reviewed the references used in these articles to identify other relevant sources. The third author adjudicated any discrepancies over whether to include an article. All articles that described and/or evaluated methods of pharmacy preceptor development, either for introductory pharmacy practice experience (IPPE) or advanced pharmacy practice experience (APPE) students or pharmacy residents, were included in the literature review. Teaching certificate programs not focused solely on preceptor development were excluded from this analysis.

\section{RESULTS}

Thirty-two articles were identified for inclusion in the review, with the subject of the articles divided between pharmacy student preceptor development and pharmacy resident preceptor development. The inclusion and exclusion of literature is highlighted in Figure 1.

\section{Pharmacy Student Preceptor Development}

Twenty-four articles regarding preceptor development related to pharmacy student experiential training were identified for inclusion (Table 1). Nineteen were analytical studies and five were descriptive in nature. ${ }^{9,14-36}$ The delivery methods used for the majority of the preceptor development programs described were either live, webbased, or multifaceted (eg, web-based and live delivery).

A cross-sectional analysis of an experiential education administrator's survey reported on preceptor orientation and development data from 85 respondents. ${ }^{36}$ Globally, about two thirds of schools offered some type of live preceptor development programming, and $75 \%$ of schools contracted with an outside vendor to deliver preceptor continuing education, such as the Pharmacist's Letter. The cost of the preceptor development program was also reported, with the majority of respondents spending more than $\$ 2500$. Outcomes of the strategies used by schools was not collected. ${ }^{36}$

A multifaceted approach to preceptor development was undertaken in five studies. ${ }^{9,18,30,32,33}$ Most incorporated some live and/or printed preceptor development component, as well as web-based modules. Boyle and colleagues described development of but did not evaluate an "academy of preceptors," which involved increased preceptor of the year recognition, networking, and development, and emphasized the value of the role that preceptors play in pharmacy education. ${ }^{33}$ Another article 


\section{American Journal of Pharmaceutical Education 2020; 84 (10) Article 7991.}

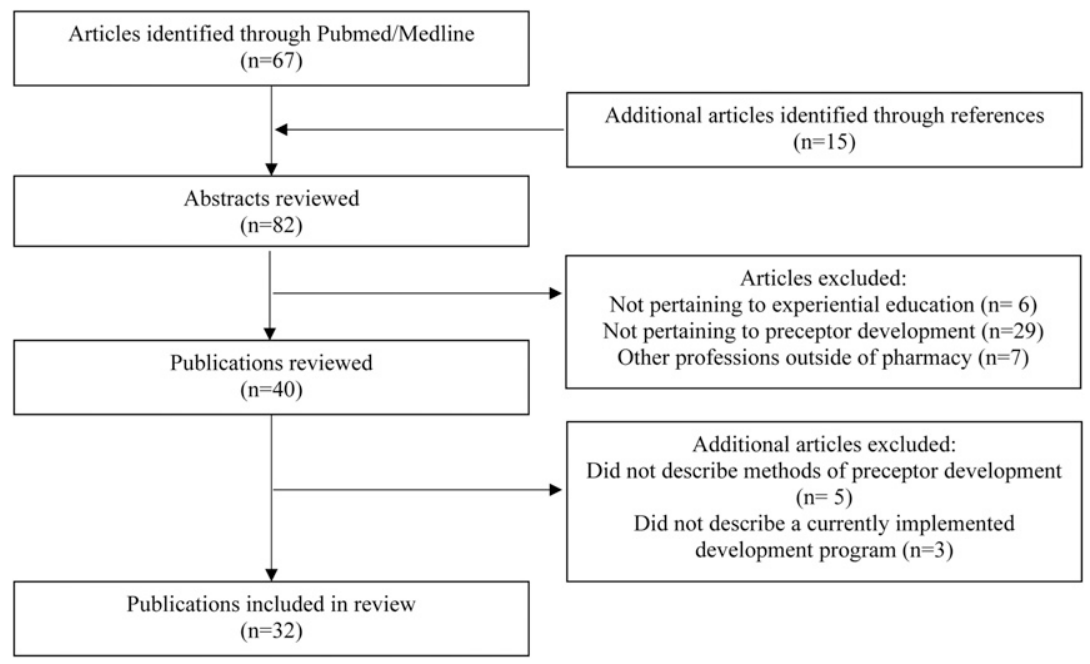

Figure 1. Study Design Flow Chart

described a longitudinal professional development program offered to pharmacists and residents, a quarter of which was focused specifically on precepting. ${ }^{30}$ In addition to in-person modules, participants had take-home assignments and were assigned a specific teaching mentor to guide them. Although multiple delivery methods were used in these studies, only Davison and colleagues investigated preceptors' preferences regarding delivery methods for training and discovered that the majority of respondents preferred online or web-based training compared with a yearly live development session. ${ }^{18}$

Six studies describe implementation of standalone live preceptor development sessions that ranged from three to 20 hours of contact time. ${ }^{14,15,17,22,23,31}$ Three were focused not only on preceptor development, but also on elevating the skills and patient care capabilities of outpatient pharmacists. ${ }^{14,15,17}$

Program evaluation methods varied among the studies. In one program described by Kassam and colleagues, after preceptors had undergone training, the school developed an enhanced advanced community experience and compared student evaluations of the enhanced experience with evaluations by a control group of students (the only study to do so). The authors found significant improvement in students' skills and attitudes compared to those of students in the control group who had completed traditional community experiences and whose preceptors had not received additional training. ${ }^{17}$ The Birkman Method training was employed in another study which sought to improve faculty and preceptor selfawareness and confidence, and to apply these skills to communication with students during experiential activities. While faculty and non-faculty preceptors were analyzed separately, improvements in confidence in numerous areas were seen in both groups. ${ }^{31}$
Six studies described using only web-based modules for preceptor development, two of which were collaborations between multiple schools. ${ }^{16,20,21,24,27,28}$ One of the studies used an already existing ACPE continuing professional development webcast for their preceptors, while others created their own material, providing anywhere from one to 11 modules for preceptor home use. $^{24,28}$ Inconsistent outcomes were investigated in these analyses, and reported participation ranged from 32 to 444 pharmacy preceptors.

Notably, four articles focused on preceptor development in interprofessional education (IPE). ${ }^{25,26,29,35}$ McCutchen and colleagues used a unique method of an interprofessional objective structured teaching exercise (iOSTE) to train 23 community pharmacy preceptors in interprofessional practice and precepting. ${ }^{26}$ Cox and colleagues also implemented a novel approach by creating a mini-series of videos screened as a feature length film for preceptors to learn interprofessional precepting skills. ${ }^{25}$ Finally, Tanzer and colleagues created an interprofessional precepting dashboard from survey results to inform specific preceptor development recommendations. ${ }^{35}$ Both McCutchen, Cox, and Fusco demonstrated significant improvements in preceptor confidence after implementation of their preceptor development strategy or program. ${ }^{25,26,29}$

\section{Pharmacy Residency Preceptor Development}

Ten articles on pharmacy residency preceptor development were identified (Table 2), including two analytical studies, three needs assessment surveys, and five descriptive publications. ${ }^{13,22,34,37-43}$ In-person training, either through concentrated or longitudinal timeframes, was described in five of ten articles and preceptor mentorship was described in four of ten articles. No studies 
American Journal of Pharmaceutical Education 2020; 84 (10) Article 7991.

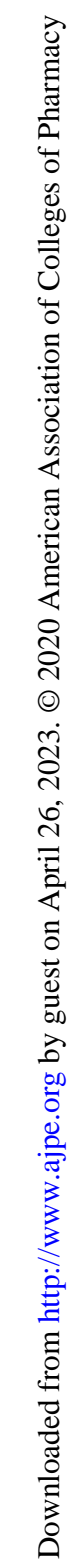

|
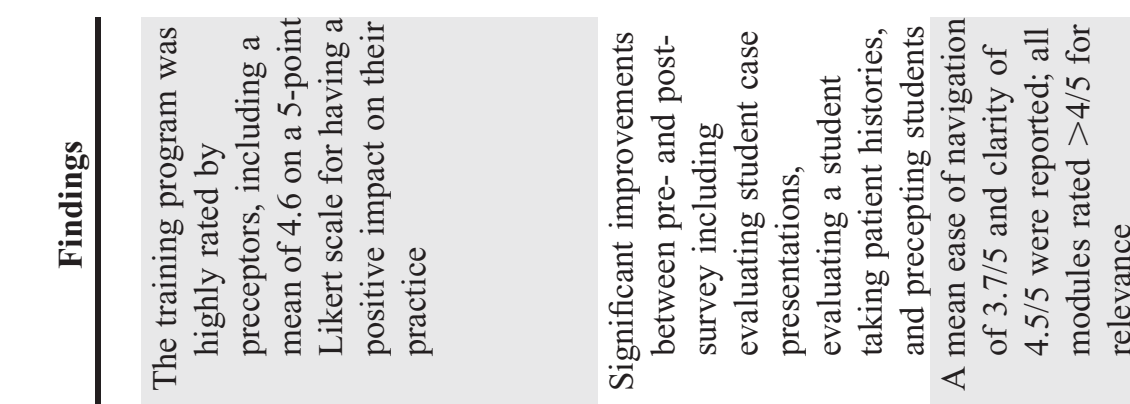

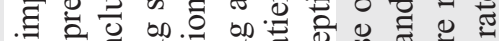

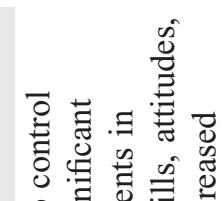

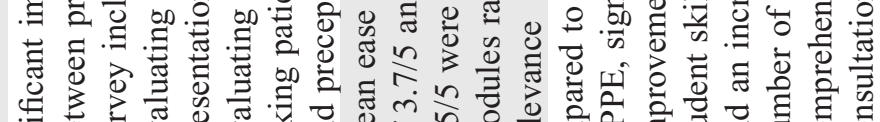

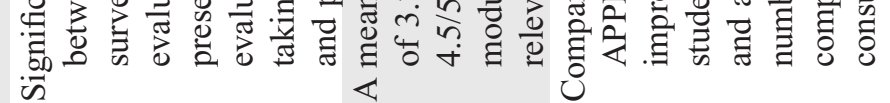

$\underset{z}{\check{z}}$

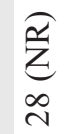

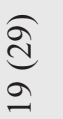

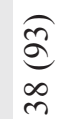
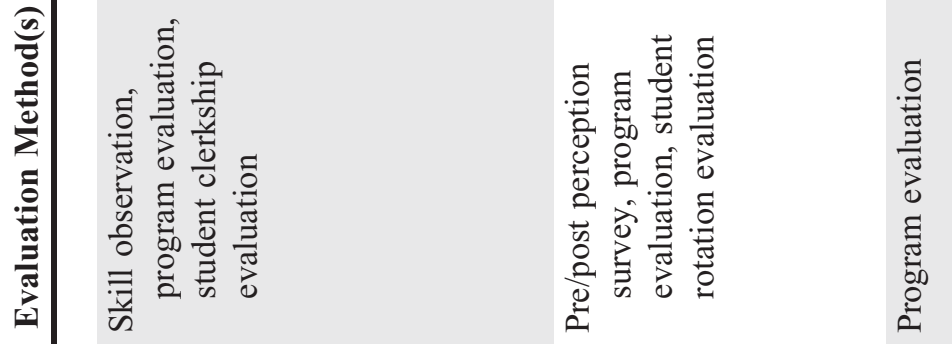

फें

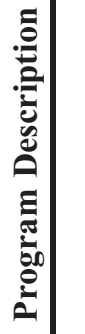

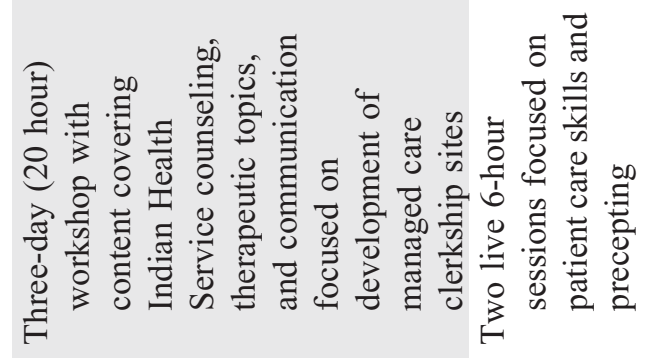

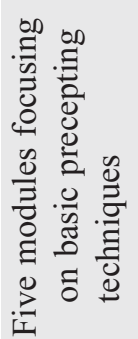

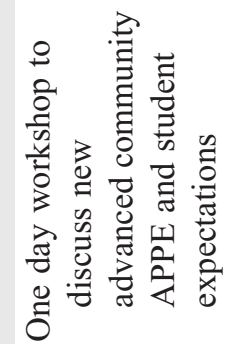

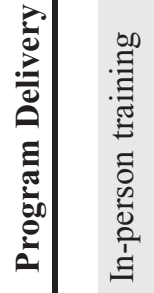

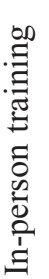

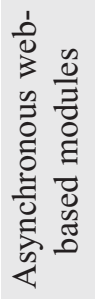

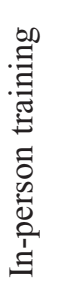

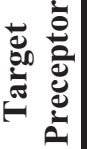

窟

突

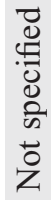

.음

营 苞.

究

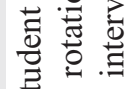

咅

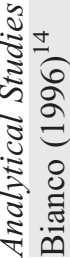

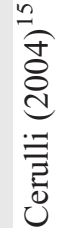

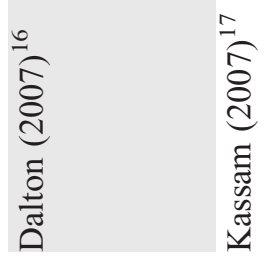


American Journal of Pharmaceutical Education 2020; 84 (10) Article 7991.

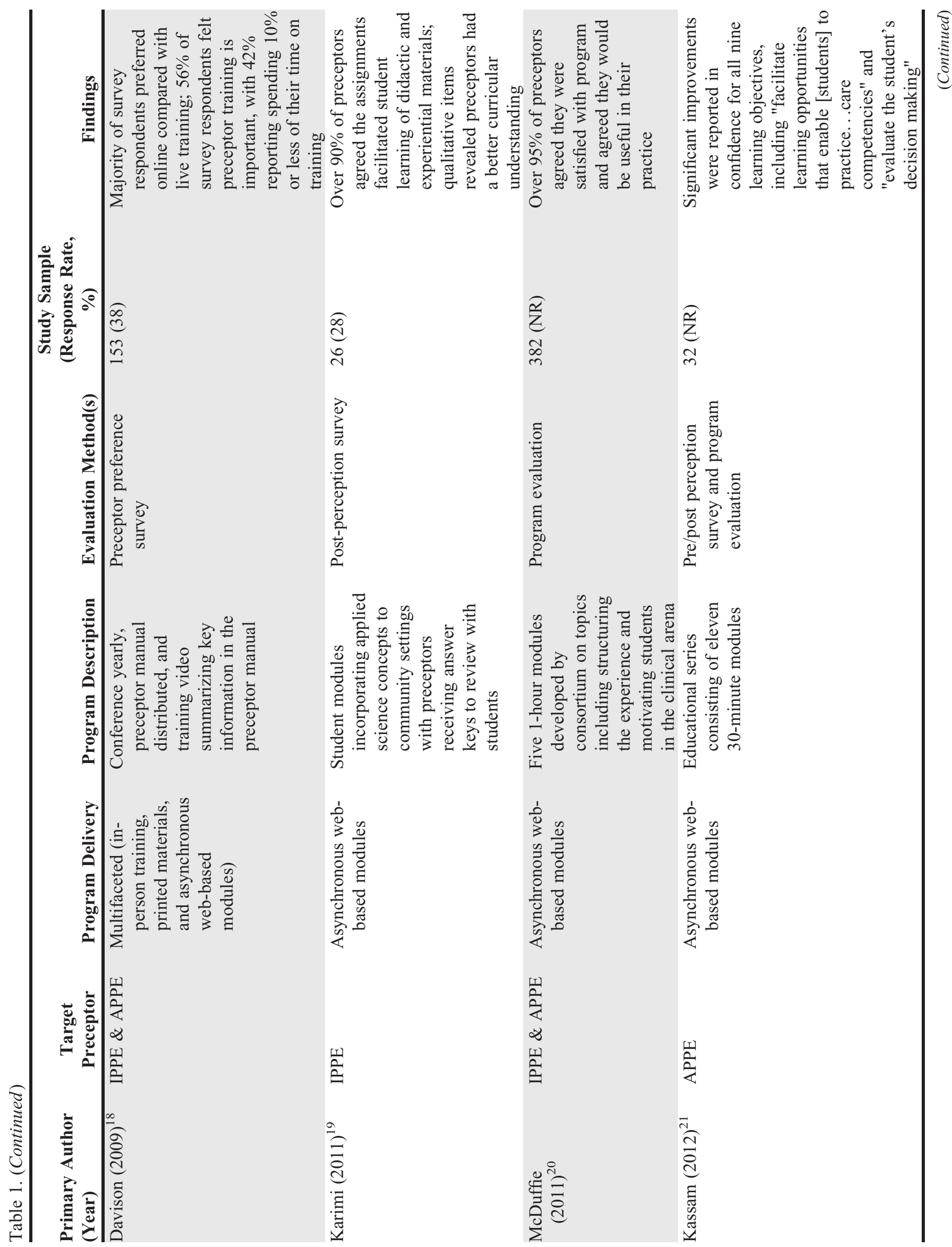


American Journal of Pharmaceutical Education 2020; 84 (10) Article 7991.

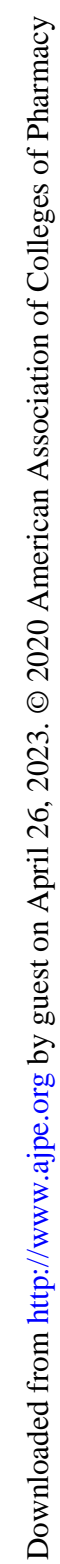

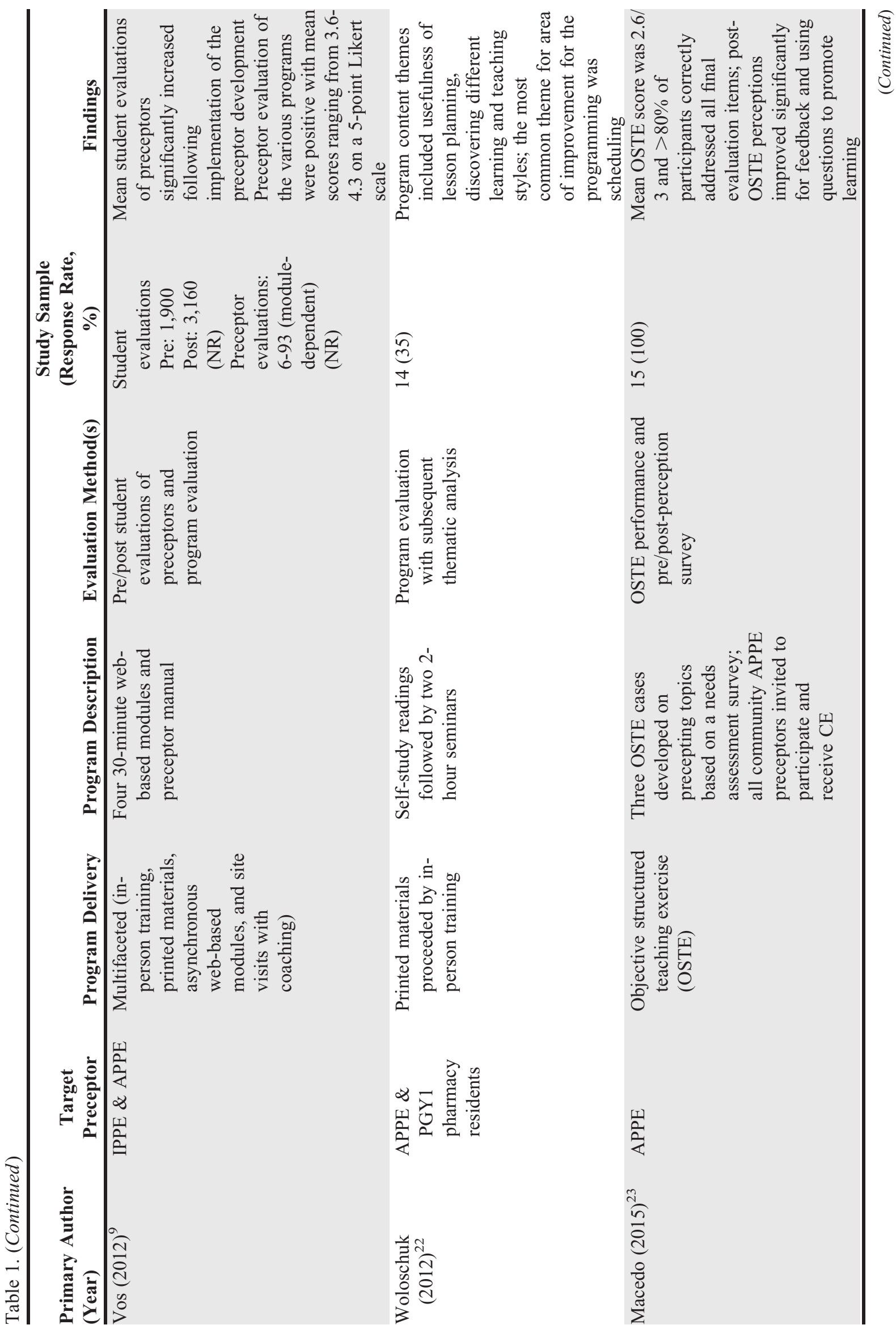

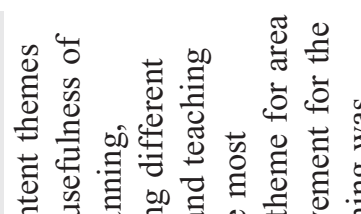

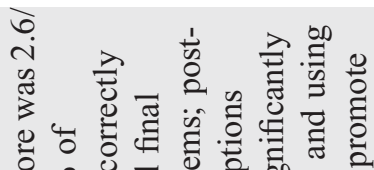

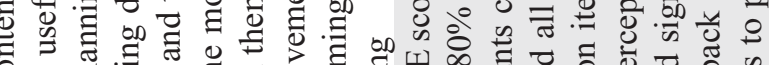

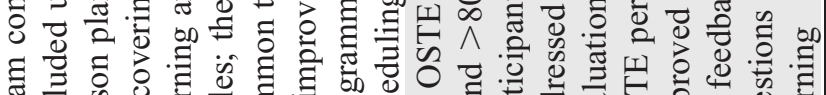

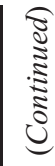


American Journal of Pharmaceutical Education 2020; 84 (10) Article 7991.

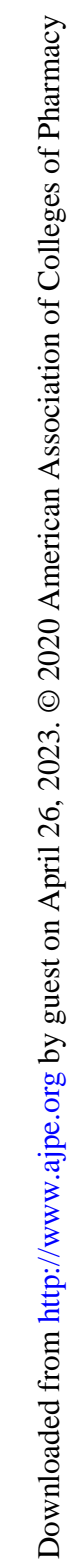

赵

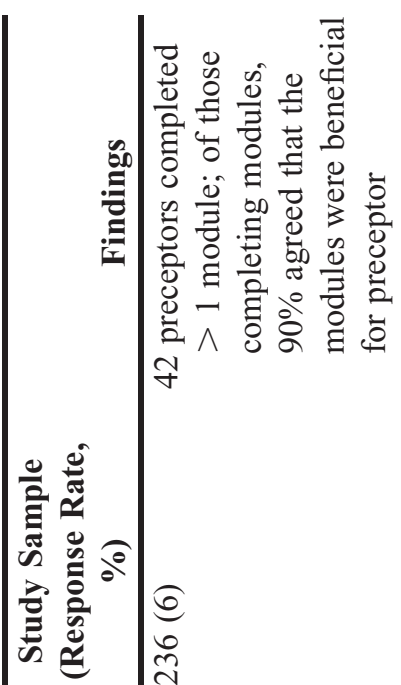

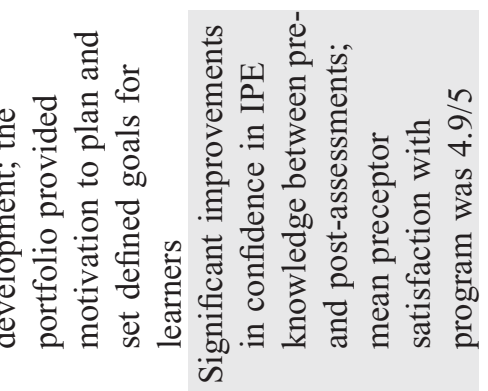

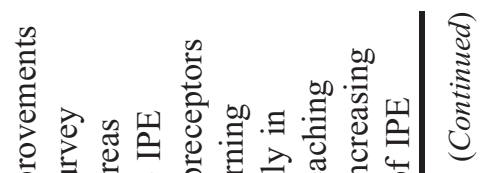

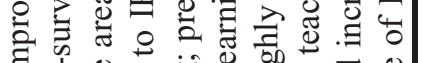

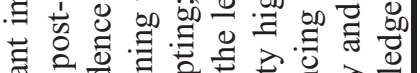

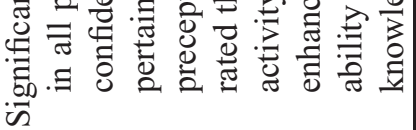


American Journal of Pharmaceutical Education 2020; 84 (10) Article 7991.

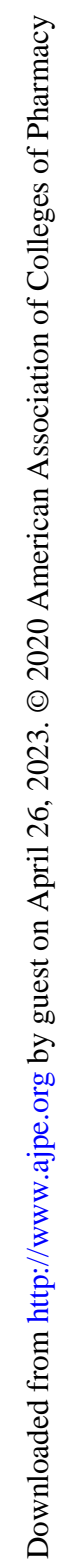

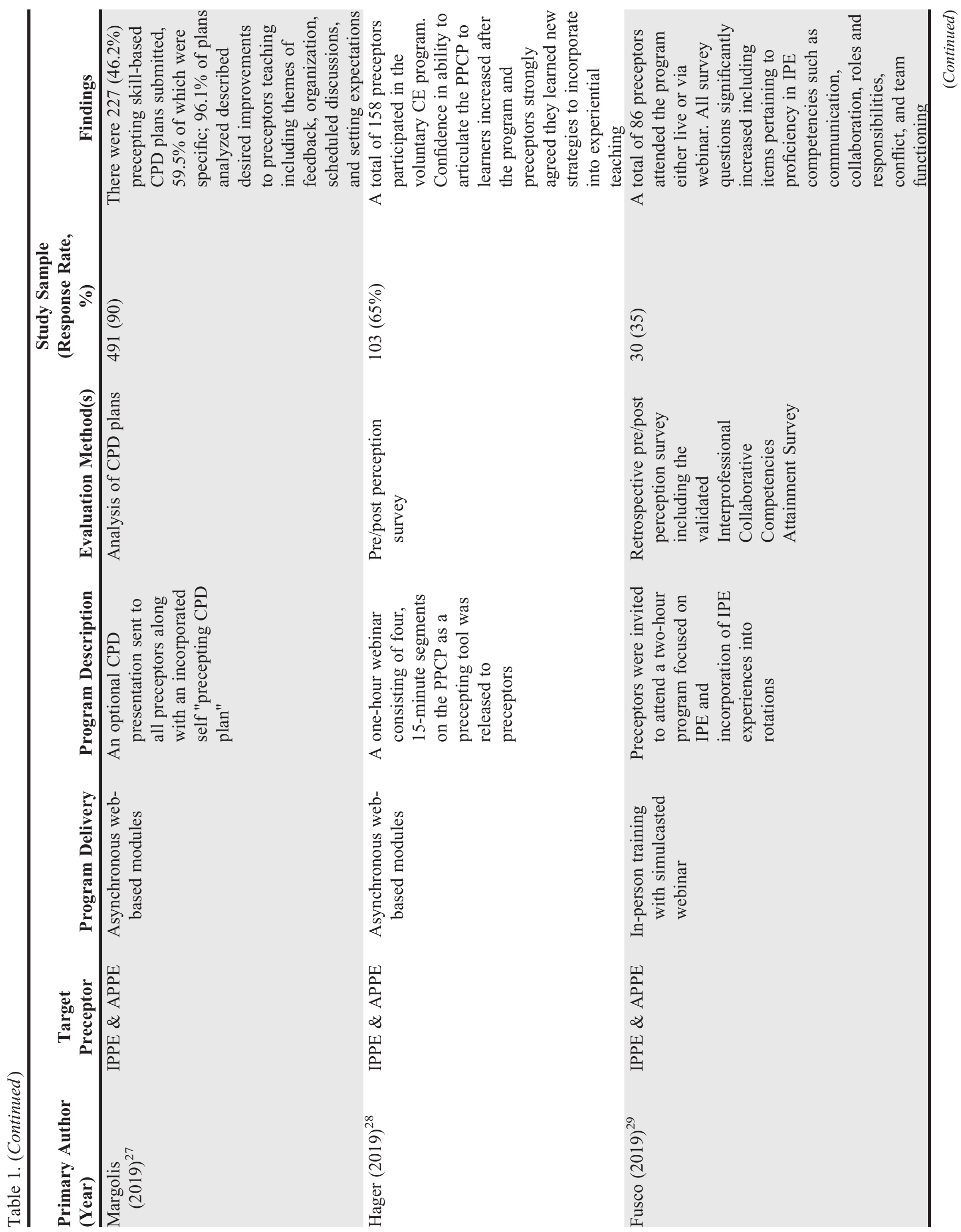


American Journal of Pharmaceutical Education 2020; 84 (10) Article 7991.

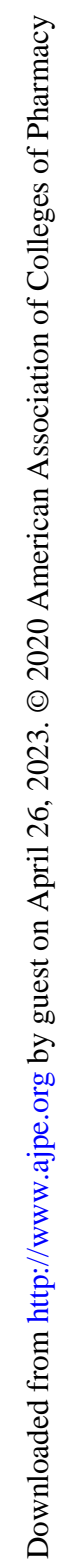

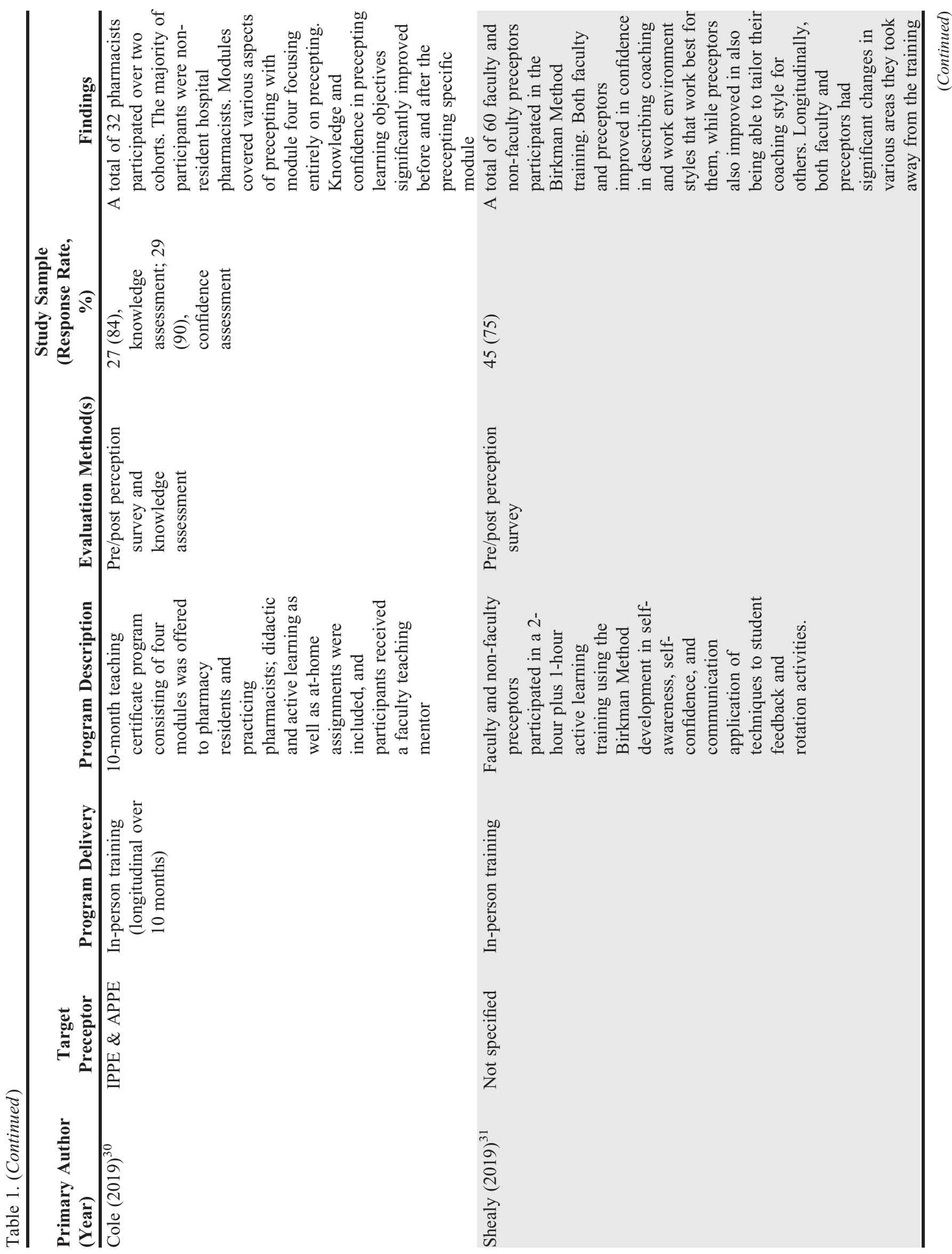


American Journal of Pharmaceutical Education 2020; 84 (10) Article 7991.

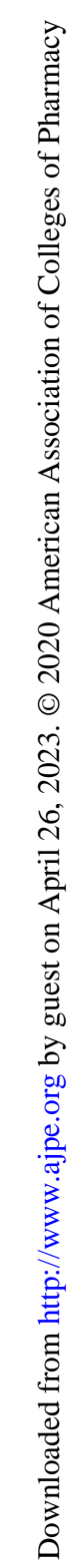

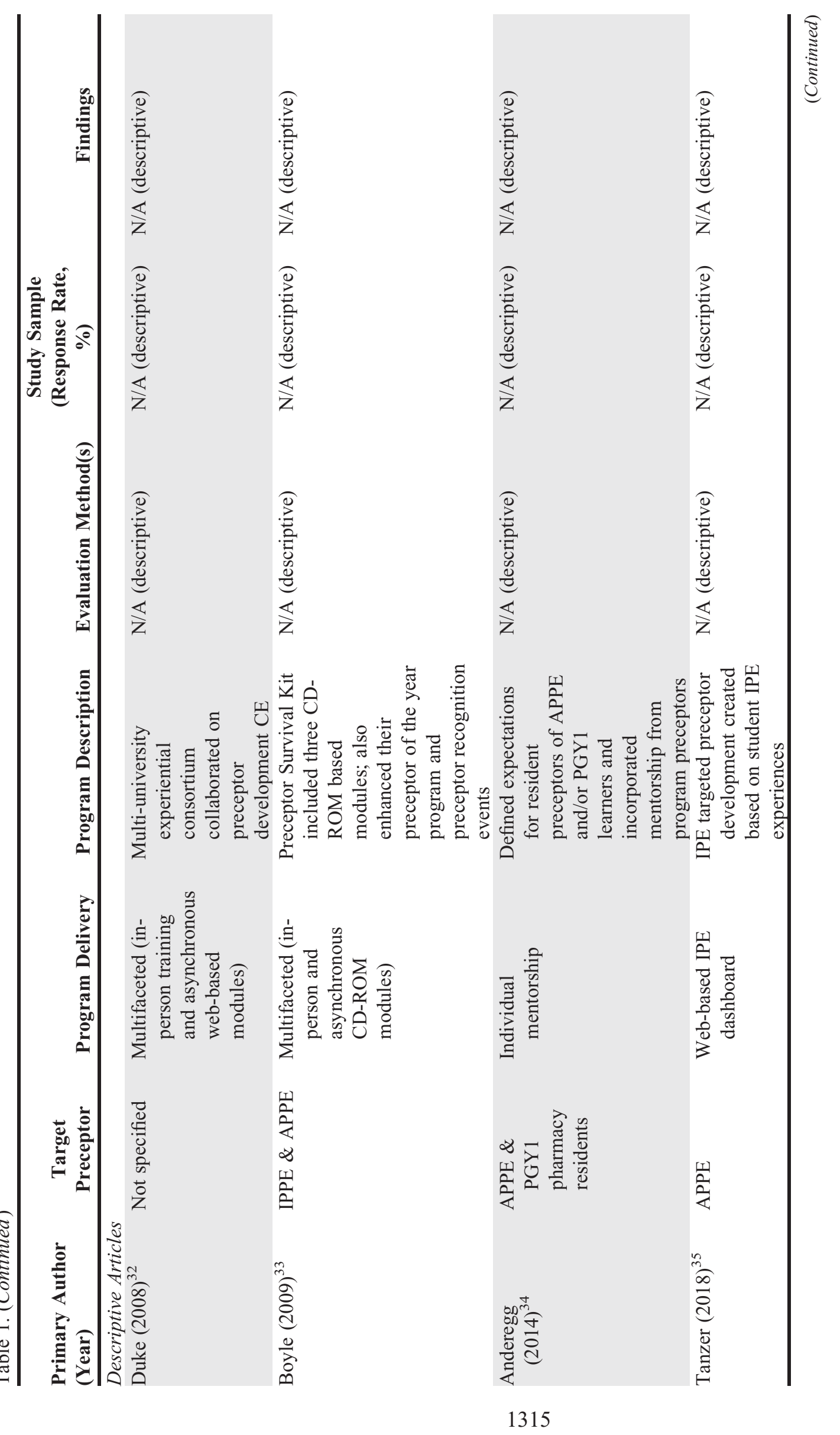




\section{American Journal of Pharmaceutical Education 2020; 84 (10) Article 7991.}

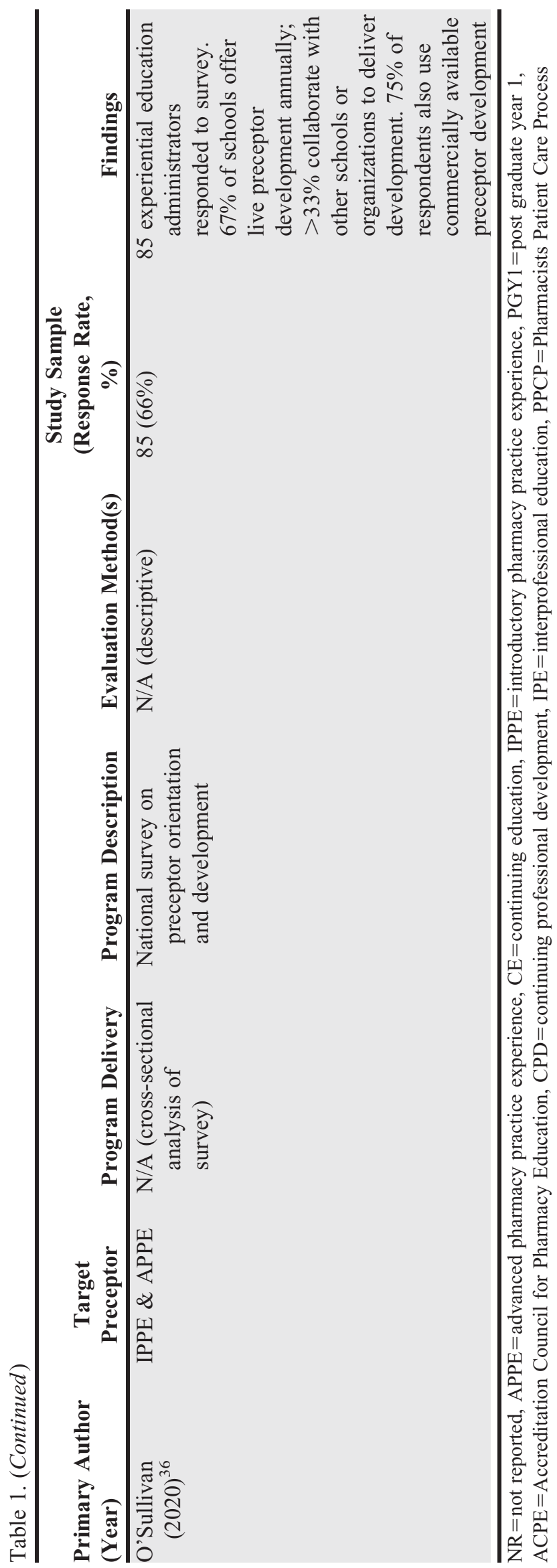

that compared delivery modalities for preceptor development programming were found. Additionally, only the two analytical students provided any assessment data, highlighting a gap in the literature ${ }^{22,37}$ Remaining literature mainly describe the structure of preceptor development programs.

Three articles on pharmacy residency needs assessments within Canada and the United States were found. ${ }^{13,38,39}$ These articles highlight the importance of including mentorship as well as internal and external preceptor training programs. However, one survey included preceptors as well as residents and did not include a response rate, while another study had a small sample and low response rate. ${ }^{13,39}$ The survey by Bolt and colleagues identified a lack of standardization within programming for pharmacy residency preceptor development. $^{39}$

\section{DISCUSSION}

We found that preceptor development strategies vary among pharmacy schools and residency programs, with some commonality in themes. Although preceptor development is a required portion of accreditation for both pharmacy schools and residency program, the literature does not support any one approach to providing it. ${ }^{1-3}$ The majority of literature pertains to development of preceptors to train pharmacy students, with both individual schools and consortiums reporting on small- and largescale programs. Residency program preceptor development, on the other hand, is less frequently evaluated and appears to follow a more individualized approach.

No standard method for preceptor development was identified among pharmacy school or residency programs. A 2015 analysis of challenges facing pharmacy experiential programs highlighted preceptor development and quality assurance as a concern for programs, especially among large and very large colleges of pharmacy. ${ }^{7}$ Given that adult learning styles and preferences vary, particularly among different generations, there may not be a best way to deliver preceptor development. ${ }^{44,45}$ Online delivery may be preferred by most pharmacy student preceptors as it was the most commonly used modality either alone or in combination. ${ }^{18}$ Additionally, needs assessments of residency preceptors have identified that there is a desire for preceptor development which may include individual mentorship or workshops and modules. $^{13,37}$

Most pharmacy schools and residency programs target preceptor development individually; however, one national effort has been described. The Canadian Experiential Education (CanExEd) Project for Pharmacy, a project through the Association of Faculties of Pharmacy, 
American Journal of Pharmaceutical Education 2020; 84 (10) Article 7991.

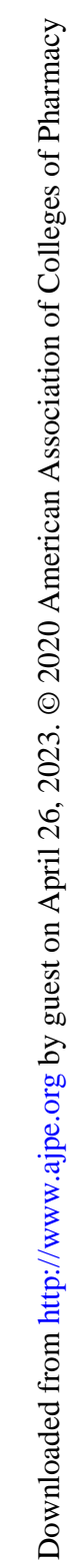

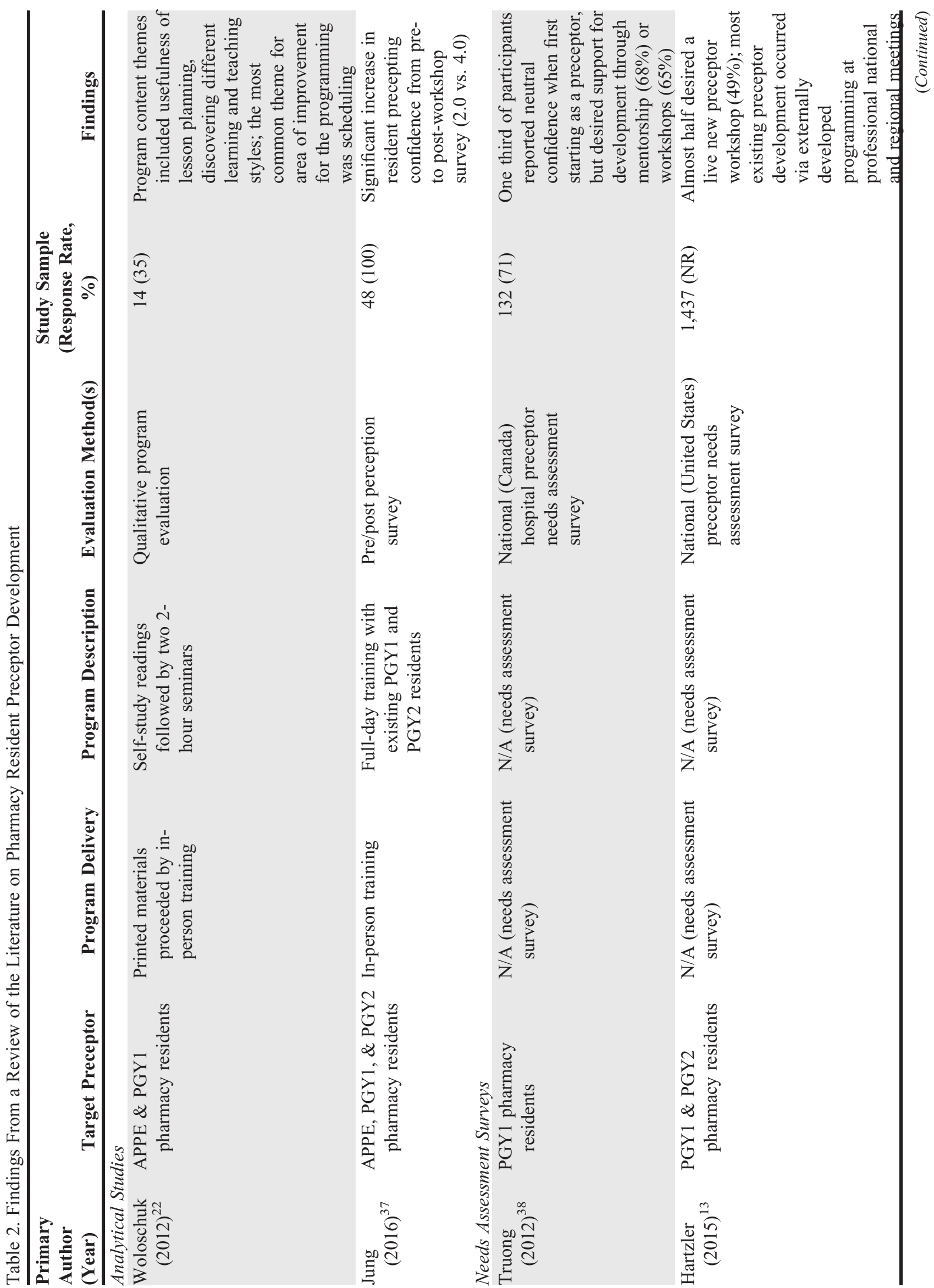


American Journal of Pharmaceutical Education 2020; 84 (10) Article 7991.

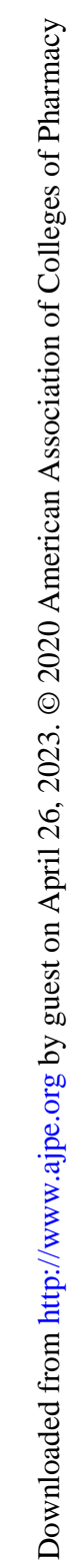
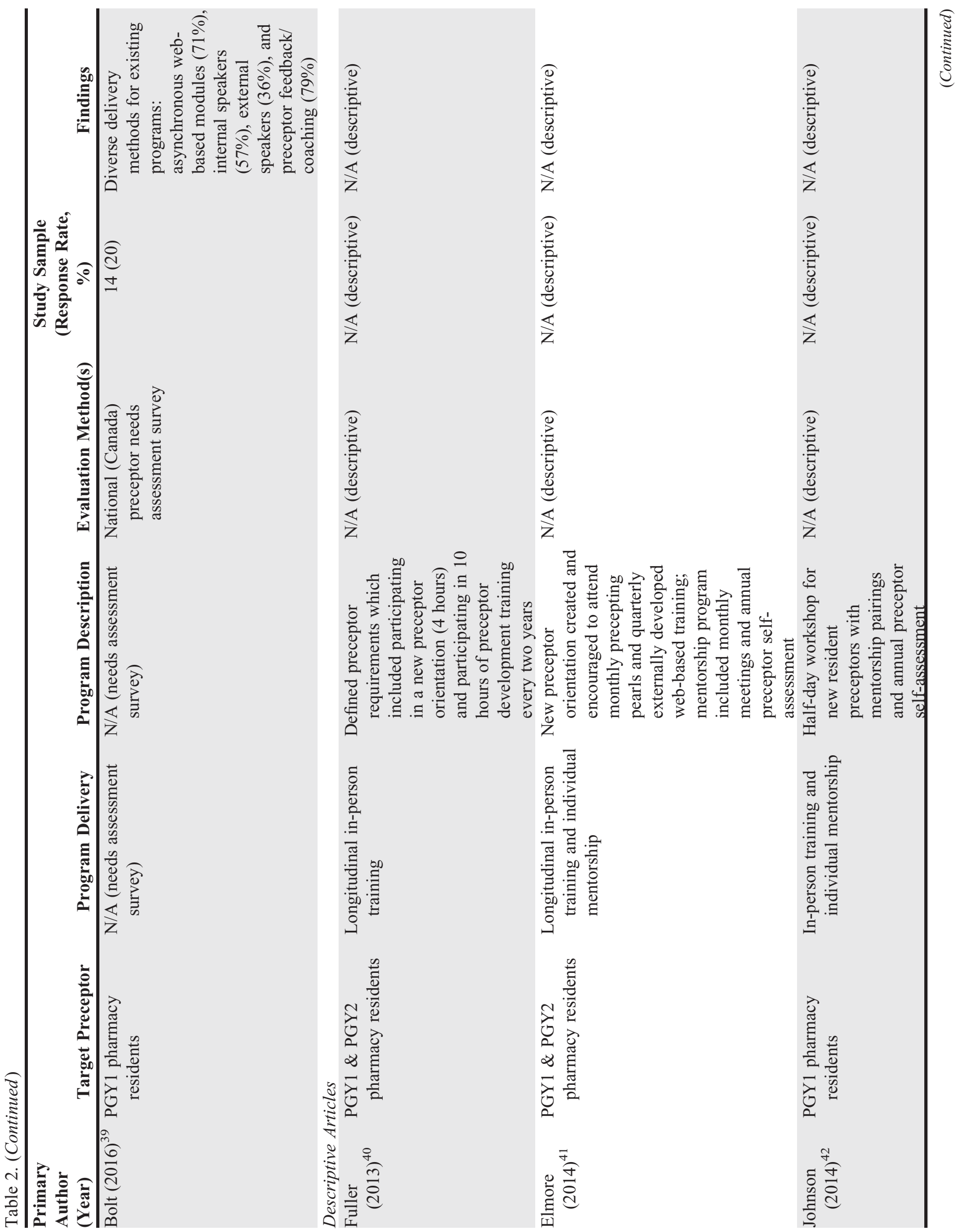

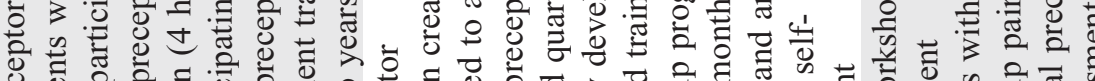

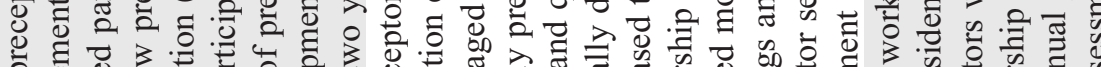

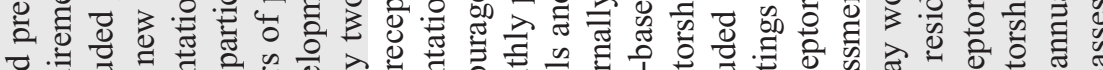

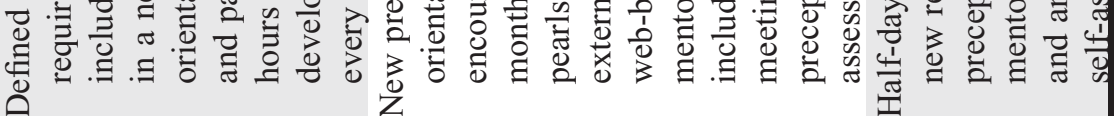
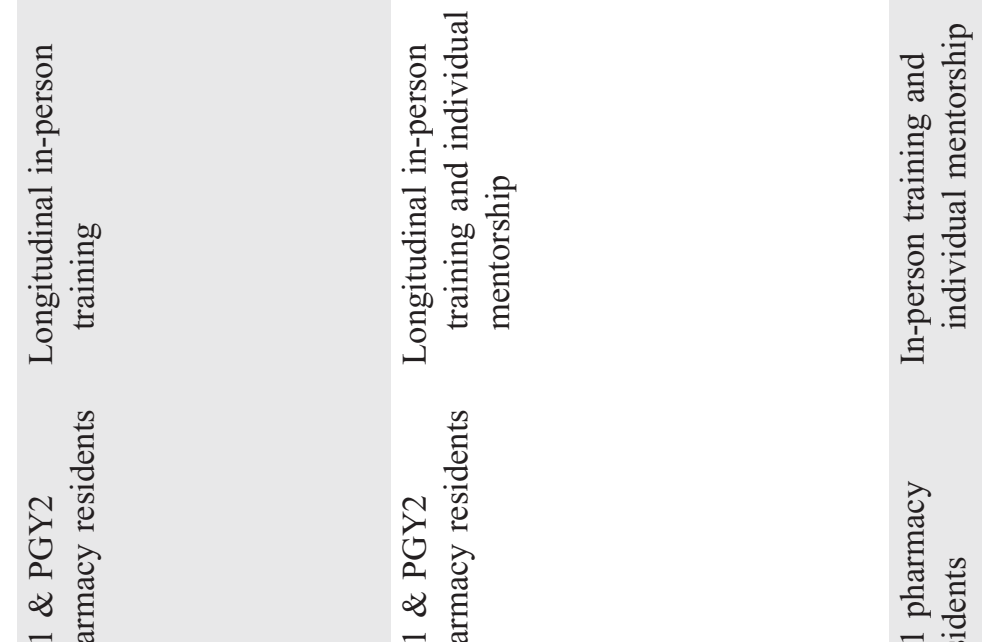

氙䒕

: 구
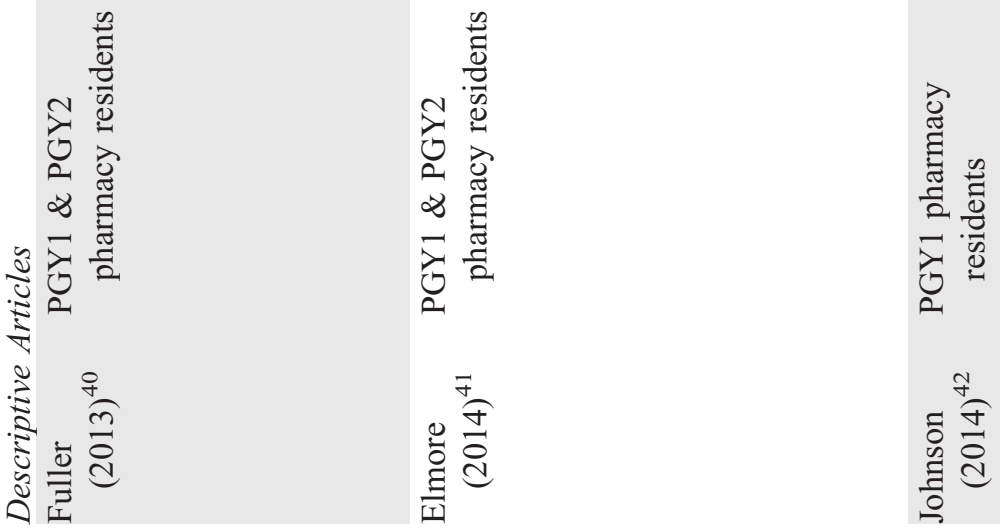

疍 
American Journal of Pharmaceutical Education 2020; 84 (10) Article 7991.

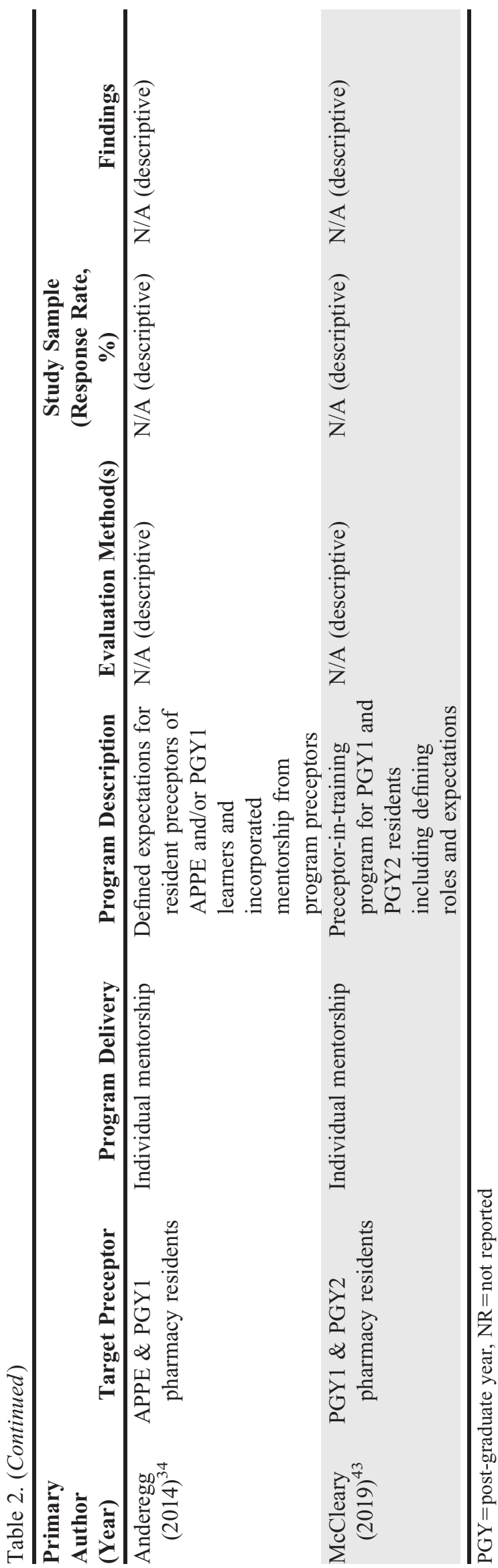

has published articles on their determination of best practices and recommendations for experiential education preceptor development in Canadian colleges of pharmacy. ${ }^{46-48}$ The resulting national preceptor development prototype encompassed three driving principles, including the importance of preceptor competencies throughout the program, strategies for preceptor engagement, and a design that allowed for continuous quality improvement and assurance measures. The webbased platform prototype allows for demographic collection followed by institution specific learning, rotation-specific training, and preceptor self-directed continuous professional development. While the final design of the described prototype has yet to be reported, this represents a step towards streamlined preceptor development that has not been described elsewhere.

Most preceptor development delivery methods have included web-based and in-person training. The ACCP white paper on quality experiential education recommends the development of web-based training programs tailored to school needs and objectives, especially as a means to standardize preceptor training. ${ }^{4}$ Both web-based and in-person training are convenient to deliver, but it is also important for pharmacy schools and residency programs to think innovatively when targeting development opportunities. There is a need within the Academy for empiric studies comparing delivery methods for preceptor development. With an increasing focus of all health professions on interprofessional education and care, the importance of preceptor development in these areas has grown. Several colleges of pharmacy have integrated interprofessional practice into preceptor development using skills-based practice, such as an interprofessional objective structured teaching exercise..$^{25,26,29,35}$ Other novel methods of development included having preceptors attend a screening of a videotaped mini-series, $A d$ ventures in Interprofessional Precepting. ${ }^{25}$ Outside of standard lectures and workshops, individual mentorship of new preceptors has been described by residency programs and within a formal teaching certificate-like program for pharmacists. ${ }^{30,34,41-43}$ While this may not be practical for colleges of pharmacy on a broad scale, it does highlight a targeted approach to preceptor development that allows programs to focus on preceptors' specific areas of need.

In addition to delivery, it is important to identify the impact of preceptor development strategies. Articles reporting on evaluation-related outcomes varied; however, the majority used preceptor pre- and post-program evaluations or perceptions surveys. Preceptor evaluations of development programs are vital as preceptors are the consumer; however, they tell us little about the impact on 


\section{American Journal of Pharmaceutical Education 2020; 84 (10) Article 7991.}

precepting skills or the impact on pharmacy learners. Unfortunately, little is known regarding the impact of pharmacy preceptor development on learner outcomes. Kassam and colleagues investigated student evaluation of rotations, finding that students' attitudes about and skills learned during a community APPE improved significantly after the preceptors attended a one-day workshop compared to a control APPE. ${ }^{17}$ Vos and colleagues also investigated student evaluations of preceptors, finding that mean student evaluations of preceptors improved following preceptor development. ${ }^{9}$ The scholarship related to preceptor development is lacking, and this is a major need for the Academy to address to enable pharmacy schools and residency programs to implement evidence-based precepting practices. Gathering more data on experiential endpoints, including student outcomes and preceptor evaluations, will help to further assess the impact of preceptor development initiatives.

Challenges that may exist for programs providing quality and wide-reaching preceptor development include preparation of and delivery time for content, geographic limitations to live delivery, cost for $\mathrm{CE}$ accreditation, cultivation of preceptor engagement and interest, and varied levels of preceptor experience, among others. While no "magic bullet" has been discovered, many of these challenges may be overcome through methods described in the literature and reported in this paper. Web-based approaches allow preceptors to access content at their convenience, regardless of their geographic location, and to learn at their own pace. Though not specifically reported here, the web-based approach also provides a time-efficient method for those delivering the preceptor development as modules may be reused for many years and accessed "on demand" and updated as needed. Multi-university consortiums or regional preceptor development is another way to pool resources and maximize personnel time. ${ }^{32}$ Preceptor development may also be focused by skill level, including development of targeted workshops for less experienced preceptors or modules on basic precepting techniques versus focusing on specific needs for more advanced preceptors, such as expanding interprofessional education. ${ }^{14,16,25,26}$

\section{CONCLUSION}

A wide array of development strategies exist for pharmacy student and resident preceptors, spanning from individual preceptor mentorship and in-person lectures and workshops to web-based modules. No specific method of delivery is recommended by accreditation bodies, allowing for flexibility and customization by pharmacy schools and residency programs. Limited evidence exists pertaining to learner outcomes, and no single strategy has emerged as superior from the varied evaluation methods reported. Schools and colleges of pharmacy and residency programs should consider resources, preceptor needs, and desired outcomes when designing preceptor development. Additionally, further assessment of the impact of preceptor development on IPPEs and APPEs, as well as on residency learning experiences, learning outcomes, and precepting skills is needed.

\section{REFERENCES}

1. Accreditation Council for Pharmacy Education. 2016. Accreditation Standards and Key Elements for the Professional Program in Pharmacy Leading to the Doctor of Pharmacy degree. https://www.acpe-accredit.org/pdf/Standards2016FINAL.pdf. Accessed September 25, 2020.

2. American Society of Health-System Pharmacists. Guidance document for the ASHP accreditation standard for postgraduate year one (PGY1) pharmacy residency programs. https://www.ashp.org/-/ media/ assets/professional-development/ residencies/docs/ guidancedocument- PGY1-standards.ashx?la=en\&

hash=23ED7EE0D27EED ADF11B7FEE9E2B2 07D9B04BCFA. Accessed September 25, 2020.

3. American Society of Health-System Pharmacists. Guidance document for the ASHP accreditation standard for postgraduate year two (PGY2) pharmacy residency programs. https://www.ashp.org/-/ media/assets/professional-development/residencies/docs/pgy2guidance document.ashx?la $=$ en $\&$ hash $=52 \mathrm{D} 0 \mathrm{~B} 7 \mathrm{CE}$

0253D49A6298C0F068D07F3BA9E3608E. Accessed September 25, 2020.

4. Haase KK, Smythe MA, Orlando PL, Resman-Targoff BH, Smith LS. Quality experiential education. Pharmacotherapy.

2008;28(10):219e-227e

5. Skrabal M, Jones RM, Nemire RE. National survey of volunteer pharmacy preceptors. Am J Pharm Educ. 2008;72(5):Article 112. 6. Bond R, Godwin D, Thompson ME, Wittstrom K. Preceptor perceptions of the importance of experiential guidelines. Am J Pharm Educ. 2013;77(7):Article 144.

7. Danielson J, Craddick K, Eccles D, Kwasnik A, O'Sullivan TA. A qualitative analysis of common concerns about challenges facing pharmacy experiential education programs. Am J Pharm Educ. 2015;79:79(1):Article 6.

8. Worrall CL, Aistrope DS, Cardello EA, et al. Priming the preceptor pipeline: collaboration, resources, and recognition: the report of the 2015-2016 Professional Affairs Standing Committee. Am J Pharm Educ. 2016;80(9):Article S19.

9. Vos SS, Trewet CLB. A comprehensive approach to preceptor development. Am J Pharm Educ. 2012;76(3):Article 47.

10. Lamontagne RL, Ginsburg DB. Legal and ethical aspects of practice. In: Cuellar LM, Ginsburg DB, eds. Preceptor's Handbook for Pharmacists. 3rd ed. Bethesda, MD: American Society of HealthSystem Pharmacists; 2016:151-170.

11. Sonthisombat P. Pharmacy student and preceptor perceptions of preceptor teaching behaviors. Am J Pharm Educ. 2008;72(5):Article 110.

12. Brody DS, Ryan K, Kuzma MA. Promoting the development of doctoring competencies in clinical settings. Fam Med.

2003;36:S105-109. 


\section{American Journal of Pharmaceutical Education 2020; 84 (10) Article 7991.}

13. Hartzler ML, Ballentine JE, Kauflin MJ. Results of a survey to assess residency preceptor development methods and precepting challenges. Am J Health-Syst Pharm. 2015; 72:1305-1314.

14. Bianco T, Haxby DG, Vanderveen RP, Boyce R, Lee NL, Muilenburg N. Development of ambulatory clerkships in a managed care setting. Am J Pharm Educ.1996;60:48-52.

15. Cerulli J, Briceland LL. A streamlined training program for community pharmacy advanced practice preceptors to enable optimal experiential learning opportunities. Am J Pharm Educ. 2004;68 (1):Article 9.

16. Dalton L, Bull R, Taylor S, Galbraith K, Marriott J, Howarth H. Evaluation of the national pharmacy preceptor education program.

Aust J Rural Health. 2007;15:159-165

17. Kassam R, Poole G, Collins JB. Development of an instrument to assess the impact of an enhanced experiential model on pharmacy students' learning opportunities, skills and attitudes: a retrospective comparative-experimentalist study. BMC Med Educ. 2008, 8:17 doi:10.1186/1472-6920-8-17

18. Davison M, Medina MS, Ray NE. Preceptor preferences for participating in electronic preceptor development. Pharm Pract (Granada). 2009;7(1):47-53.

19. Karimi R, Cawley P, Arendt CS. Learning bridge tool to improve student learning, preceptor training, and faculty teamwork. Am J Pharm Educ. 2011;75(3):Article 46.

20. McDuffie CH, Duke LJ, Stevenson L, et al. Consortium-based approach to an online preceptor development program. Am J Pharm Educ. 2011;75(7):Article 135.

21. Kassam R, Kwong M, Collins JB. An online module series to prepare pharmacists to facilitate student engagement in patientcentered care delivery: development and evaluation. Adv Med Educ Prat. 2012:3.61-71.

22. Woloschuk DMM, Raymond CB. Development and evaluation of a workplace-based preceptor training course for pharmacy practitioners. Can Pharm J (Ott). 2012;145(5):231-236.

23. Macedo L, Sturpe DA, Haines ST, Layson-Wolf C, Tofade TS, McPherson ML. An objective structured teaching exercise (OSTE) for preceptor development. Curr Pharm Teach Learn.

2015;7:627-634.

24. Tofade T, Kim J, Lebovitz L, et al. Introduction of a continuing professional development tool for preceptors: lessons learned. $J$ Pharm Pract. 2015;28(2) 212-219.

25. Cox CD, Samuel NG, Cheon J. Use of an innovated interprofessional mini-series movie to train preceptor. Innovations in Pharmacy. 2017;8(2):Article 17.

26. McCutcheon LRM, Whitcomb K, Cox CD, et al.

Interprofessional objective structured teaching exercise (iOSTE) to train preceptors. Curr Pharm Teach Learn. 2017;9:605-615.

27. Margolis A, Bruskiewitz R, Kieser M. Preceptor fidelity to the creation of precepting-focused continuing professional development learning plans. Innovations in Pharmacy. 2019;10(2):Article 2.

28. Hager KD, Schlichte A, Frail CK. This is how I think: evaluation of a preceptor development webinar on incorporating the

Pharmacists' Patient Care Process into experiential teaching. Curr Pharm Teach Learn. 2019;11(11):1132-1137.

29. Fusco NM, Ohtake PJ. Training the trainers: a preceptor development program targeting interprofessional collaboration competencies. Curr Pharm Teach Learn. 2019;11(11):1138-1143.
30. Cole JD, Ruble MJ, Wantuch G, et al. Effectiveness of a pharmacy teaching certificate program offered to practicing pharmacists. Curr Pharm Teach Learn. 2019;11(11):1152-1158. 31. Shealy SC, Worrall CL, Baker JL, et al. Assessment of a faculty and preceptor development intervention to foster self-awareness and self-confidence. Am J Pharm Educ. 2019;83(7):Article 6920.

32. Duke LJ, Unterwagner WL, Byrd DC. Establishment of a multistate experiential pharmacy program consortium. Am J Pharm Educ. 2008;72(3):Article 62.

33. Boyle CJ, Morgan JA, Layson-Wolf C, Rodriguez de Bittner M. Developing and implementing an academy of preceptors. Am J Pharm Educ. 2009;73(2):Article 34.

34. Anderegg SV, Christenson JC, Padgett CP. An accelerated, practice-based model for fostering precepting skills in pharmacy residents. Hosp Pharm. 2014;49(8):713-716.

35. Tanzer KD, Dintzner MR. The IPE performance report: a tool for preceptor development. Curr Pharm Teach Learn. 2018;10:584-595. 36. O'Sullivan TA, Cox CD, Darbishire P, et al. The status and adequacy of preceptor orientation and development programs in US pharmacy schools. Am J Pharm Educ. 2020;84(2):Article 7540. 37. Jung CM, Ansara ED, Degenkolb KE, Walroth TA, Williams KE. Development of a precepting workshop for pharmacy residents. Am J Health-Syst Pharm. 2016;72:127-132.

38. Truong C, Wyllie A, Bailie T, Austin Z. A needs assessment study of hospital pharmacy residency preceptors. Can J Hosp Pharm. 2012;65(3):202-208.

39. Bolt J, Baranski B, Bell A, Semchuk WM. Assessment of preceptor development strategies across Canadian pharmacy residency programs. Can J Hosp Pharm. 2016;69(2):144-148. 40. Fuller PD, Peters LL, Hoel R, Baldwin JN, Olsen KM. Residency preceptor development and evaluation: a new approach. Am J HealthSyst Pharm. 2013;70:1605-1608.

41. Elmore L, Blair M, Edgerton L. Preceptor development strategies used in a mixed academic-community teaching hospital. Curr Pharm Teach Learn. 2014;6:167-173.

42. Johnson JL, O'Neal KS, Condren ME. An initiative to transition new faculty from resident to residency preceptor through direct mentorship. Curr Pharm Teach Learn. 2014;6:589-594.

43. McCleary EJ, Thompson Bastin ML, Bissell BD, Cook AM, Pierce CA, Flannery AH. Development of a coprecepting model for a preceptor-in-training program for new practitioners. Hosp Pharm. 2019;54(4):246-249.

44. Loewen PS, Jelescu-Bodos A. Learning styles and teaching perspectives of Canadian pharmacy practice residents and faculty preceptors. Am J Pharm Educ. 2013;77(8):Article 163.

45. Romanelli F, Bird E, Ryan M. Learning styles: a review of theory, application, and best practices. Am J Pharm Educ.

2009;73(1):Article 9.

46. Mulherin K, Walter S, Cox C. National preceptor development program (PDP): influential evidence and theory. The first of a 3-part series. Curr Pharm Teach Learn. 2018;10:255-266.

47. Walter S, Mulherin K, Cox C. A preceptor competency framework for pharmacists. Part 2 of a 3-part series. Curr Pharm Teach Learn. 2018;10:402-410.

48. Cox C, Mulherin K, Walter S. National preceptor development program (PDP) prototype. The third of a 3-part series. Curr Pharm Teach Learn. 2018;10:298-306. 